\title{
Preparation of a new micro-mesoporous omega zeolite by hydrothermal route: Effect of crystallization time
}

Nabila Bouchiba ( $\square$ aymane18@yahoo.fr)

Universite d'Oran 1 Ahmed Ben Bella

Nadia Toumi

Centre Universitaire Nour Bachir, El Bayadh, Algér

Abdelkader Bengueddach

Universite d'Oran 1 Ahmed Ben Bella

\section{Short Report}

Keywords: zeolite, mazzite, micro-mesoporous materials, hierarchical zeolite

Posted Date: April 30th, 2021

DOl: https://doi.org/10.21203/rs.3.rs-440863/v1

License: (c) (1) This work is licensed under a Creative Commons Attribution 4.0 International License.

Read Full License

Version of Record: A version of this preprint was published at Silicon on July 12th, 2021. See the published version at https://doi.org/10.1007/s12633-021-01254-6. 


\section{Abstract}

This work concerns the preparation of a new micro-mesoporous omega zeolite by hydrothermal route. This method consists of the self-assembly of the omega zeolite precursors with a cethyltrimethylammonium bromide surfactant. Different stages of crystallization were studied in order to determine their impact on the textural and structural properties of the resulting materials. For this, several characterization methods were used such as X-ray diffraction, $\mathrm{N}_{2}$ adsorption/desorption, scanning electron microscopy, and Energy-Dispersive X-ray. The results showed that the processing time significantly influences on the crystallinity, porosity and Si/Al ratio of the resulting materials. A specific surface area almost three times greater than the parent zeolite was obtained when using nonhydrothermally treated zeolite precursors. While the precursors prepared hydrothermally for 48 hours or 72 hours essentially lead to the formation of the microporous phase corresponding to the Omega zeolite.

These new properties can open new applications of these solids notably in the catalysis for the conversion of bulky molecules and also in the adsorption of organic and organic pollutants.

\section{Introduction}

Zeolites have been widely used as adsorbents and catalysts in many chemical and petro-chemical processes due to their excellent properties such as higher acidity, hydrothermal stability, and form selectivity $[1,2]$. However, the own presence of micropores in zeolites often imposes diffusion restrictions related to the intracrystalline transport of the reactants to reach the active sites and of products to move away from these sites. In addition, the large compound cannot access in many cases the internal surface area of zeolite, which limits their use as catalysts in important chemical processes $[3,4]$.

An alternative solution to deal with bulky substrates has been the synthesis of ordered mesoporous materials which possess uniform mesopores that can be varied in a wide range $[5,6]$, the synthesis of nanosized zeolites [7] and ultra large-pore zeolites [8].

Nevertheless, the application of these materials is fairly limited because of the difficult separation of nanosized zeolite crystals from the synthesis medium, the low acidity and hydrothermal stability of mesoporous molecular sieve materials and the need of employing Geranium, as well as the addition of special template in the synthesis of ultra-large-pore zeolite $[9,10]$.

One of the most successful strategies to overcome the above disadvantages is to prepare micro/mesoporous material. By this way, both advantages of large pore size of mesoporous materials and strong acidity and high hydrothermal stability of zeolites would be combined. Several successful routes for synthesizing composites with excellent catalytic performances have been reported in literatures $[11,12]$.

Omega zeolite or ZSM-4, the synthetic analog of mazzite is a large-pore (7.5^) zeolite having hexagonal pummatm, with n ailinn aluminn matin / $\left.c_{i} / \Lambda / l\right)$ in the intermediate range (3-5). Omega framework contains Loading [MathJax]/jax/output/CommonHTML/jax.js 
gmelinite cages bridged by oxygen atoms to give a 12-membered cylindrical channel system along the crystallographic $c$-axis. Due to its high acidity and unique structural features, omega zeolite received much attention as catalyst and adsorbent [13-18]. To date, to improve the textural properties of the omega zeolite, researchers have turned to dealumination of this zeolite. However, it has been shown in several studies that this method leads to a decrease in the acidity strength, which subsequently influences on its catalytic performance.

In this work, and for the first time, the micro-mesoporous omega zeolite was prepared by assembling the precursors of the omega zeolite obtained at different stages of crystallization and then modified with a $\mathrm{CTABr}$ surfactant to form the mesoporous phase. The textural and structural properties of the materials obtained have been correlated and discussed.

\section{Materials And Methods}

\subsection{Reagents}

Reactants used in the synthesis were: Sodium aluminate $\left(54 \% \mathrm{Al}_{2} \mathrm{O}_{3}, 41 \% \mathrm{Na}_{2} \mathrm{O} ; 5 \% \mathrm{H}_{2} \mathrm{O}\right.$; Aldrich), porous silica gel powder (Fluka), tetraethoxisillane (TEOS 98\%, Aldrich), cetyl trimethylammonium bromide $\left(\mathrm{C}_{19} \mathrm{H}_{42} \mathrm{NBr}, \mathrm{CTAB} 99 \%\right)$, tetramethylammonium hydroxide (TMAOH. $5 \mathrm{H}_{2} \mathrm{O}, 97 \%$, Aldrich), sodium hydroxide pellets ( $\mathrm{NaOH} 99 \%$ Sigma-Aldrich), hydro-chloric acid ( $\mathrm{HCl} 36-37 \mathrm{wt} \%$, Prolabo) and the demineralized water.

\subsection{Synthesis micro-mesoporous omega zeolite}

The micro-mesoporous omega zeolite was synthesized as follows: $0.48 \mathrm{~mol}$ of $\mathrm{NaOH}, 0.77 \mathrm{~mol}$ of TMAOH and $0.32 \mathrm{~mol}$ of $\mathrm{NaAlO}_{2}$ were dissolved in $18.67 \mathrm{~mol}$ of $\mathrm{H}_{2} \mathrm{O}$. To this mixture $0.17 \mathrm{~mol}$ of silica was added. The resulting solution was stirred at room temperature for $17 \mathrm{~h}$ and then hydrothermally treated at $383 \mathrm{~K}$ for various periods of time ( $0 \mathrm{~h}, 48 \mathrm{~h}$ and $72 \mathrm{~h}$ ). After cooling at room temperature, $10 \mathrm{~g}$ of the resulting precursors were added drop wise to $27 \mathrm{~g}$ solution of cetyl-trimethylammonium bromide (CTAB, $4 \mathrm{wt} . \%$ aqueous solution) and then stirred vigorously. Subsequently, the $\mathrm{pH}$ value of the synthetic mixture was adjusted to 9 with $\mathrm{HCl}$. The obtained mixture was stirred at room temperature for $15 \mathrm{~min}$ and then heated for $24 \mathrm{~h}$ at $383 \mathrm{~K}$. The obtained materials were filtered, washed extensively, dried and calcined at $823 \mathrm{~K}$ for $8 \mathrm{~h}$ to remove organic template.

\subsection{Synthesis of omega zeolite}

The method of preparing the omega zeolite has been well detailed in the work published previously. Briefly a solution containing $0.48 \mathrm{~mol}$ of $\mathrm{NaOH}, 0.77 \mathrm{~mol}$ of TMAOH, $0.32 \mathrm{~mol}$ of $\mathrm{NaAlO}_{2}$ and $18.67 \mathrm{~mol}$ of $\mathrm{H}_{2} \mathrm{O}$. Then $0.17 \mathrm{~mol}$ of silica $\left(\mathrm{SiO}_{2}\right)$ was added and stirred for $17 \mathrm{~h}$ at room temperature. The mixture was transferred into an autoclave for crystallization at $383 \mathrm{~K}$ for $72 \mathrm{~h}$. The obtained zeolite was recovered by filtration, dried and then calcined at $823 \mathrm{k}$ for 6 hours to remove the organic template. 
The XRD powder diffraction patterns of the obtained samples were obtained by a Bruker AXS D-8 diffractometer using $\mathrm{Cu}$-Ka radiation. Both low- and wide-angle $\mathrm{X}$-ray patterns were recovered to assess the order of the mesopores and the crystallinity of the microporous phase in the different samples. Nitrogen adsorption-desorption isotherms at $77 \mathrm{~K}$ of the calcined samples were measured by a Micromeritics TRISTAR 3000 V6.04 A instrument. The surface area was calculated by the BrunauerEmmett-Teller (BET) method [19]. The pore size distributions were determined by the Barrett-JoynerHalenda (BJH) method using the adsorption branch of the isotherms [20]. The microporous volume was obtained from the t-plot analysis [21, 22]. The energy dispersive X-ray analysis (EDX) jointed to a XL-30 scanning electron microscope was used to calculate the Si/Al ratio for each sample. The surface topography of the different materials was observed using SEM on a Hitachi 4800 S microscope.

\section{Results And Discussions}

\subsection{Crystal structures}

Three micro/mesoporous composites and the parent omega zeolite were prepared and their structural and textural properties were compared. The micro/mesoporous samples were obtained at different processing times of omega zeolite precursors $(0 \mathrm{~h}, 48 \mathrm{~h}$ and $72 \mathrm{~h}$ ) using the assembly of preformed zeolite omega precursors with CTABr surfactant.

The powder XRD patterns of the calcined micro/mesoporous composites and omega zeolite are presented in Fig. 1. In the high $2 \theta$ region, the diffraction peaks of the sample omega are corresponding to typical mazzite structure [23]. When the precursor zeolite species was used without a previous crystallization, the XRD pattern for the resulting material (sample $\mathrm{C}(\mathrm{Oh})$ ) indicates that a structurally well ordered hexagonal aluminosilicate was successfully assembled from omega zeolite seeds. The diffraction peak corresponding to $\left(\begin{array}{lll}1 & 0 & 0\end{array}\right)$ reflections is shifted towards lower angles, i.e. larger $\mathrm{d}$-spacing (see Table 1), compared with Al-MCM-41 indicating a higher content of aluminum in the framework [24].

Table 1

Structural properties of the calcined samples

\begin{tabular}{|llll|}
\hline Samples & Crystallization time $(\mathrm{h})$ & $\mathrm{d}_{100}(\AA)$ & Unit cell $\mathrm{a}_{0}(\AA)$ \\
\hline $\mathrm{C}(0 \mathrm{~h})$ & 00 & 40.48 & 46.8 \\
\hline $\mathrm{C}(48 \mathrm{~h})$ & 48 & 39.35 & 45.5 \\
\hline $\mathrm{C}(72 \mathrm{~h})$ & 72 & 37.75 & 43.6 \\
\hline The unit cell parameter $\mathrm{a}_{0}$ is calculated from $\mathrm{a}_{0}=2 \mathrm{~d}_{100} / \sqrt{ } 3$. \\
\hline
\end{tabular}

Extending the crystallization time of the precursor zeolite species resulted in the formation of composite materials (samples $\mathrm{C}(48 \mathrm{~h})$ and $\mathrm{C}(72 \mathrm{~h})$ ) composed of a hexagonal mesoporous phase and omega zeolite. It in nntad from thn VDn nattarm / $m$ r Fir 1) that the contribution of the microporous phase in the Loading [MathJax]/jax/output/CommonHTML/jax.js 
composite has become greater with the increase in the crystallization time. Thus, we can deduce that an extension of the crystallization time promotes the formation of the omega zeolite.

The FTIR spectra of all samples are shown in Fig. 2. As shown in this figure the infrared spectra of all samples are almost identical. The only difference is located at $3356 \mathrm{~cm}^{-1}$ and $1007 \mathrm{~cm}^{-1}$.

It is known that omega zeolite is characterized by the following bands: a broad band at $3356 \mathrm{~cm}^{-1}$ which is assigned to stretches of associated and free $\mathrm{OH}$ [15]. The band at $1632 \mathrm{~cm}^{-1}$ also corresponds to the vibrations of the $\mathrm{OH}$ group of physisorbed water molecules. Strong bands at $1007 \mathrm{~cm}^{-1}$ which is assigned to the asymmetric stretching vibrations of the $T-O$ bond $(T=S i$ or $A l)[17,18]$. Weak bands observed at 817 and $716 \mathrm{~cm}^{-1}$ which are attributed to symmetrical elongations of the T- 0 bond. The weak band at $614 \mathrm{~cm}^{-1}$ is assigned to T- 0 vibrations with 6 tetrahedra $[17,18]$. For micro-mesoporous composite materials had almost the same bands as the omega zeolite the only difference took place in the $\mathrm{T}-\mathrm{O}$ band which was shifted to the highest wave numbers $1089 \mathrm{~cm}^{-1}$ probably due to the low aluminum content which causes this displacement.

\subsection{Textural properties}

The $\mathrm{N}_{2}$ adsorption-desorption isotherms and the corresponding BJH pore size distribution curves for the calcined micro-mesoporous composites are depicted in Fig. 3. The $\mathrm{C}(\mathrm{Oh})$ and $\mathrm{C}(48 \mathrm{~h})$ samples isotherms are of type-IV [25] and exhibit three stages. The first step relating to low pressures $(P / P 0<0.25)$ reflects the monolayer adsorption of nitrogen on the walls of the mesopores. The second stage is characterized by a steep increase in the adsorbed amount at a relative pressure $\left(0.25<P / P_{0}<0.4\right)$, caused by the mesopores filling. The third stage $\left(P / P_{0}>0.4\right)$ in the adsorption isotherm is the gradual increase in volume with $\mathrm{P} / \mathrm{P}_{0}$, due to multilayer adsorption on the outer surface of the particles. The BJH pore size distribution confirms that both composites possess well defined mesopores.

The sample $C(72 h)$ shows an adsorption isotherm of type I characteristic of microporous materials and a hysteresis loop in the desorption branch which reveals the existence of mesopores. The pore size distribution profile also shows a wide distribution which confirms the existence of several and heterogeneous pores.

The textural data are presented in Table 2, it is clearly indicated that the textural properties of micromesoporous materials decrease during the increase in the duration of hydrothermal treatment of the precursors due to the domination of the miroporouse phase. 
Table 2

Textural properties of the calcined samples

\begin{tabular}{|llllll|}
\hline Samples & $\begin{array}{l}\text { Surface area } \\
\left(\mathbf{m}^{2} / \mathbf{g}\right)\end{array}$ & $\begin{array}{l}\text { Pore volume } \\
\left(\mathbf{c m}^{3} / \mathbf{g}\right)\end{array}$ & $\begin{array}{l}\text { Pore size } \mathrm{D}_{\mathrm{p}} \\
(\AA)\end{array}$ & $\begin{array}{l}\text { Wall thikness } \mathrm{D}_{\mathrm{w}} \\
(\AA)\end{array}$ & $\begin{array}{l}\text { Si/Al } \\
(\mathrm{EDX})\end{array}$ \\
\hline $\mathrm{C}(\mathrm{Oh})$ & 314 & 0.19 & 34.8 & 12.00 & 8.65 \\
$\mathrm{C}(48 \mathrm{~h})$ & 182 & 0.12 & 34.6 & 10.90 & 9.54 \\
\hline $\mathrm{C}(72 \mathrm{~h})$ & 106 & 0.06 & 33 & 10.60 & 9.90 \\
\hline $\begin{array}{l}\text { Omega } \\
\text { zeolite }\end{array}$ & 105 & 0.04 & - & - & 3.06 \\
\hline
\end{tabular}

These changes in textural properties are consistent with the gradual transformation of zeolite seed containing mesostructured phase in the composite materials. On the other hand, There was a slight increase of the wall thickness in the $\mathrm{C}(0 \mathrm{~h})$ composite $(12.07 \AA ̊ \AA)$. These results could suggest the existence of secondary building units' characteristic of omega zeolite into the mesopore wall of the composite [26].

\subsection{Electron microscopy}

The morphology of obtained samples was investigated by scanning electron microscopy (SEM). The sample $\mathrm{C}(\mathrm{Oh})$ is essentially made up of aggregated sphere shaped particles with size of smaller than $1 \mu \mathrm{m}$ (see Fig. 4). This morphology is typical of silicate mesoporous materials [27].

The SEM images of the samples $\mathrm{C}(48 \mathrm{~h})$ and $\mathrm{C}(72 \mathrm{~h})$ show the presence of hexagonal prisms shaped particles which can be assigned to omega zeolite crystals. It is found that every omega crystal is evenly embedded in the loose MCM-41 aggregates. However, the proportion of omega crystals increases with the gradual increase in the crystallization time. These results are in good agreement with nitrogen sorption measurements and XRD analysis.

\section{Conclusions}

Composite micro/mesoporous materials are interesting because they combine the advantages of mesoporous materials with those of zeolites. Using this way, a new type of molecular sieve with micromesoporous structures, was successfully prepared. The synthesis process involved the assembly of omega zeolite precursor species obtained at various stages of crystallization into a mesostructured phase. By varying the time allowed for the crystallization of the precursor zeolite species we were able to modify the composition of the composite materials. The adsorption data of nitrogen suggest the presence of micropores and mesopores in the composite materials. The mesopores diameter is slightly higher in the composite materials compared to the parent material. The results indicate a higher content of aluminum in the composites framework which can improve substantially their acidity and 
hydrothermal stability. With these properties this material can be used as a very good acid catalyst for the conversion of large molecules.

\section{Declarations}

\section{Funding}

The authors thank DGRSDT (Direction Générale de la Recherche Scientifique et du Développement Scientifique) for Financial support.

\section{Author Contributions}

All authors have contributed equally in this work.

Compliance with Ethical Standards The authors declare that all procedures followed were in accordance with the ethical standards.

Data Availability Based on the journal's policy all the data and materials of this paper are available for reader.

Research Involving Human Participants and/ or Animals Not applicable.

Informed Consent Informed consent was obtained from all individual participants included in the study.

Consent to participate We give our consent to participate.

Consent for Publication All the authors are giving consent to publish

Conflicts of Interest/Competing Interests No conflicts to report.

\section{References}

1. Vogt ETC and Weckhuysen BM. (2015) Fluid catalytic cracking: recent developments on the grand old lady of zeolite catalysis. Chem Soc Rev 44(20), 7342-7370. https://doi.org/1039/c5cs00376h.

2. Choudary NV and Newalkar BL (2011) Use of zeolites in petroleum refining and petrochemical processes: recent advances. J Porous Mater 18(6), 685-692. https://doi.org/1007/s10934-010-94278.

3. Hartmann M (2004) Hierarchical zeolites: a proven strategy to combine shape selectivity with efficient mass transport. Angew Chem Int Ed 43(44), 5880-5882. https://doi.org/1002/anie.200460644.

4. Pérez-Ramirez J, Christensen Claus H, Egeblad K, Christensen Christina H, and Groen, Johan C. (2008), "Hierarchical zeolites: enhanced utilisation of microporous crystals in catalysis by advances in materiale decian Chem Sor Rev 27(11), 2530-2542. https://doi.org/1039/b809030k. 
5. Kresge CT, Leonowicz ME, Roth WJ, Vartuli JC, Beck JS (1992) Ordered mesoporous molecular sieves synthesized by a liquid-crystal template mechanism. Nature 359(6397), 710-712. https://doi.org/1038/359710a0.

6. Martin-Aranda, Rosa M, Cejka J (2010) Recent advances in catalysis over mesoporous molecular sieves. Top Catal 53(3-4), 141-153. https://doi.org/1007/s11244-009-9419-6.

7. Valtchev V, Tosheva L (2013) Porous nanosized particles: preparation, properties, and applications. Chem Rev 113(8), 6734-6760. https://doi.org/1021/cr300439k.

8. Corma A, Diaz-Cabanas Maria J, Jorda Jose L, Martínez C, Moliner M (2006) High-throughput synthesis and catalytic properties of a molecular sieve with 18- and 10-member rings. Nature 443(7113), 842-845. https://doi.org/1038/nature05238.

9. Serrano DP, Aguado J, Escola JM, Rodriguez JM, Peral A (2008) Effect of the organic moiety nature on the synthesis of hierarchical ZSM-5 from silanized protozeolitic units. J Mat Chem 18(35), 42104218. https://doi.org/1039/B805502E.

10. Möller K, Bein T (2013) Mesoporosity - a new dimension for zeolites. Chem Soc Rev 42(9), 36893707. https://doi.org/1039/C3CS35488A.

11. Hoan Vu X, Hunger M, Armbruster U, Martin A (2018) Influence of initial Si/Al ratios on the structural, acidic and catalytic properties of nanosized-ZSM-5/SBA-15 analog composites prepared from ZSM5 precursors. J Porous Mater 25(4), 1035-1046. https://doi.org/1007/s10934-017-0514-y.

12. Aghakhani MS, Khodadadi AA, Najafi Sh, Mortazavi Y (2014) Enhanced triisopropyl-benzene cracking and suppressed coking on tailored composite of Y-zeolite/amorphous silica-alumina catalyst. J Ind Eng Chem 20(5), 3037-3045. https://doi.org/1016/j.jiec.2013.11.040.

13. Shigeishi RA, Chiche BH, Fajula F (2001) CO adsorption on superacid sites on dealuminated mazzite. Micropor Mesopor Mater 43(2), 211-226. https://doi.org/1016/s1387-1811(00)00365-6.

14. McQueen D, Chiche BH, Fajula F, Auroux A, Guimon C, Fitoussi F, Schulz P (1996) A multitechnique characterization of the acidity of dealuminated mazzite. J Catal 161(2), 587-596. https://doi.org/1006/jcat.1996.0221.

15. Terrab I, Boukoussa B, Hamacha R, Bouchiba N, Roy R, Bengueddach A, Azzouz A (2016) Insights in $\mathrm{CO}_{2}$ interaction on zeolite omega-supported polyol dendrimers. Thermochimica Acta 624 95-101.

16. Hakiki A, Boukoussa B, Kibou A, Terrab I, Ghomari K, Choukchou-Braham N, Hamacha R, Bengueddach A, Azzouz A (2018) Correlation of hydrophilic character and surface basicity of exchanged omega-catalyzed MCR process. Thermochimica Acta 662 108-115

17. Mekki A, Boukoussa B (2019) Structural, textural and toluene adsorption properties of microporousmesoporous zeolite omega synthesized by different methods. Journal of Materials Science 54 8096-8107

18. Mekki A, Mokhtar A, Hachemaoui M, Beldjilali M, Meliani MF, Habib Zahmani H, Hacini S, Boukoussa B (2021) Fe and Ni nanoparticles-loaded zeolites as effective catalysts for catalytic reduction of organic pollutants. Microporous and Mesoporous Materials 310110597 
19. Brunauer S, Emmett PH, Teller E (1938) Adsorption of gases in multimolecular layers. J Am Chem Soc 60(2), 309-319. https://doi.org/1021/ja01269a023.

20. Barrett EP, Joyner LG, Halenda PP (1951) The determination of pore volume and area distributions in porous substances. I. computations from nitrogen isotherms. J Am Chem Soc 73(1), 373-380. https://doi.org/10.1021/ja01145a126.

21. Ryoo R, Joo SH, Kruk M, Jaroniec M (2001) Ordered mesoporous carbons. Adv Mater 13(9), 677-681. https://doi.org/1002/1521-4095(200105)13:9<677::aid-adma677>3.0.co;2-c.

22. Jaroniec M, Kruk M, Olivier JP (1999) Standard nitrogen adsorption data for characterization of nanoporous silicas. Langmuir 15(6), 5410-5413. https://doi.org/1021/la990136e.

23. Treacy MMJ, Higgins JB (2007) Collection of Simulated XRD Powder Patterns for Zeolites, (5th Edition), Elsevier Science, pp 262-263. Amsterdam, The Netherlands.

24. Campos JM, Lourenço JP, Fernandes A, Rosário Ribeiro M (2008) Mesoporous Ga-MCM-41: A very efficient support for the heterogenisation of metallocene catalysts. Commun 10(1), 71-73. https://doi.org/10.1016/j.catcom.2008.07.038.

25. Matos Jivaldo J, Kruk M, Mercuri LP, Jaroniec M, Zhao L, Kamiyama T, Terasaki O, Pinnavaia T, Liu Y (2003) Ordered mesoporous silica with large cage-like pores: structural identification and pore connectivity design by controlling the synthesis temperature and time. J Am Chem Soc 125(3), 821829. https://doi.org/1021/ja0283347.

26. Guo W, Huang L, Deng P, Xue Z, Li Q (2001) Characterization of Beta/MCM-41 composite molecular sieve compared with the mechanical mixture.

27. Micropor Mesopor Mater 44-45, 427-434. https://doi.org/1016/s1387-1811(01)00217-7.

28. Li Y, Shi J, Chen H, Hua Z, Zhang L, Ruan M, Yan J, Yan D (2003) One-step synthesis of hydrothermally stable cubic mesoporous aluminosilicates with a novel particle structure. Micropo Mesopor Mater 60(1-3), 51-56. https://doi.org/1016/s1387-1811(03)00316-0.

\section{Figures}



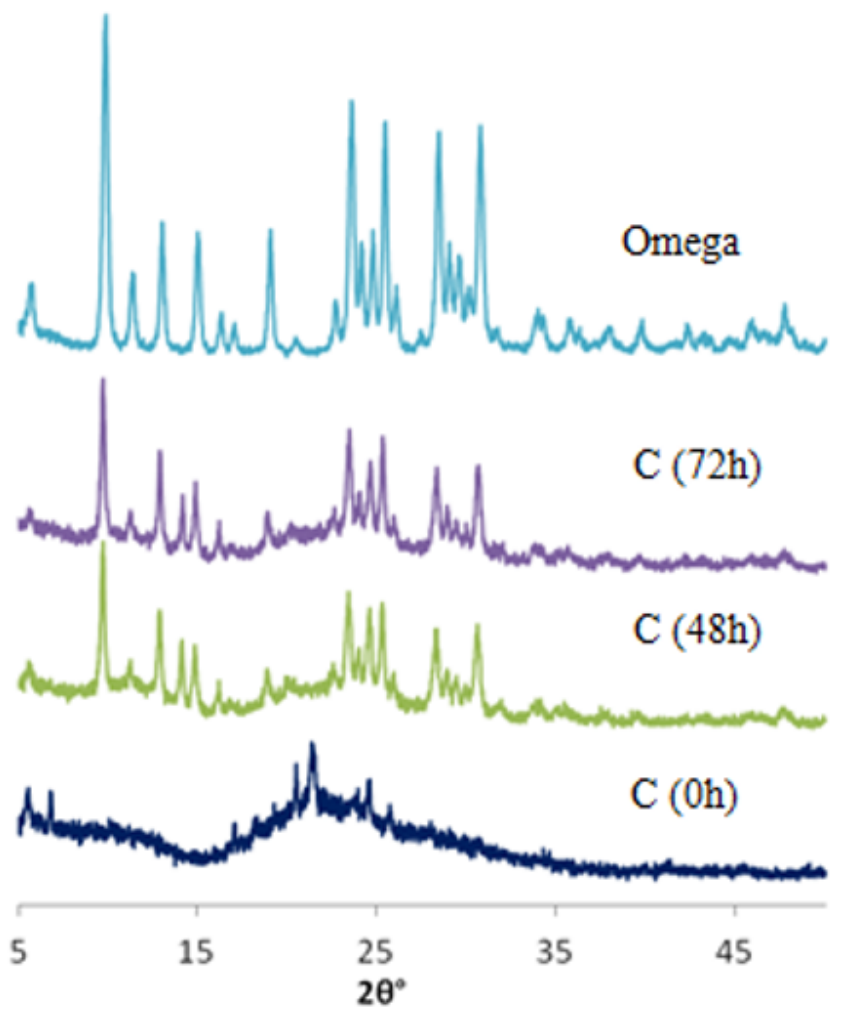

(a) Wide-angle region

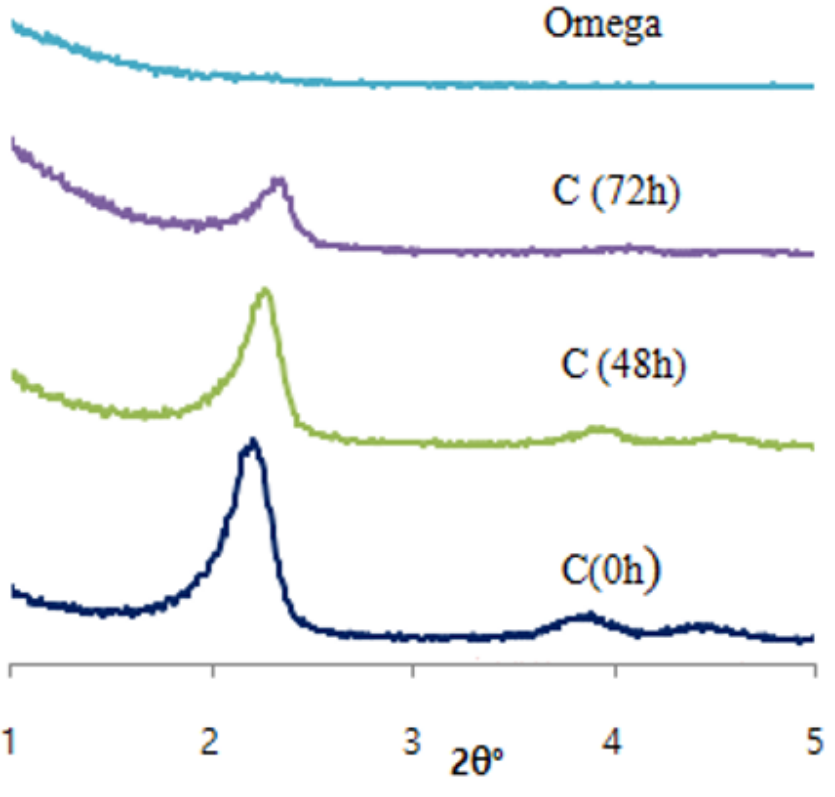

(b) Low-angle region

Figure 1

XRD patterns of the calcined samples 


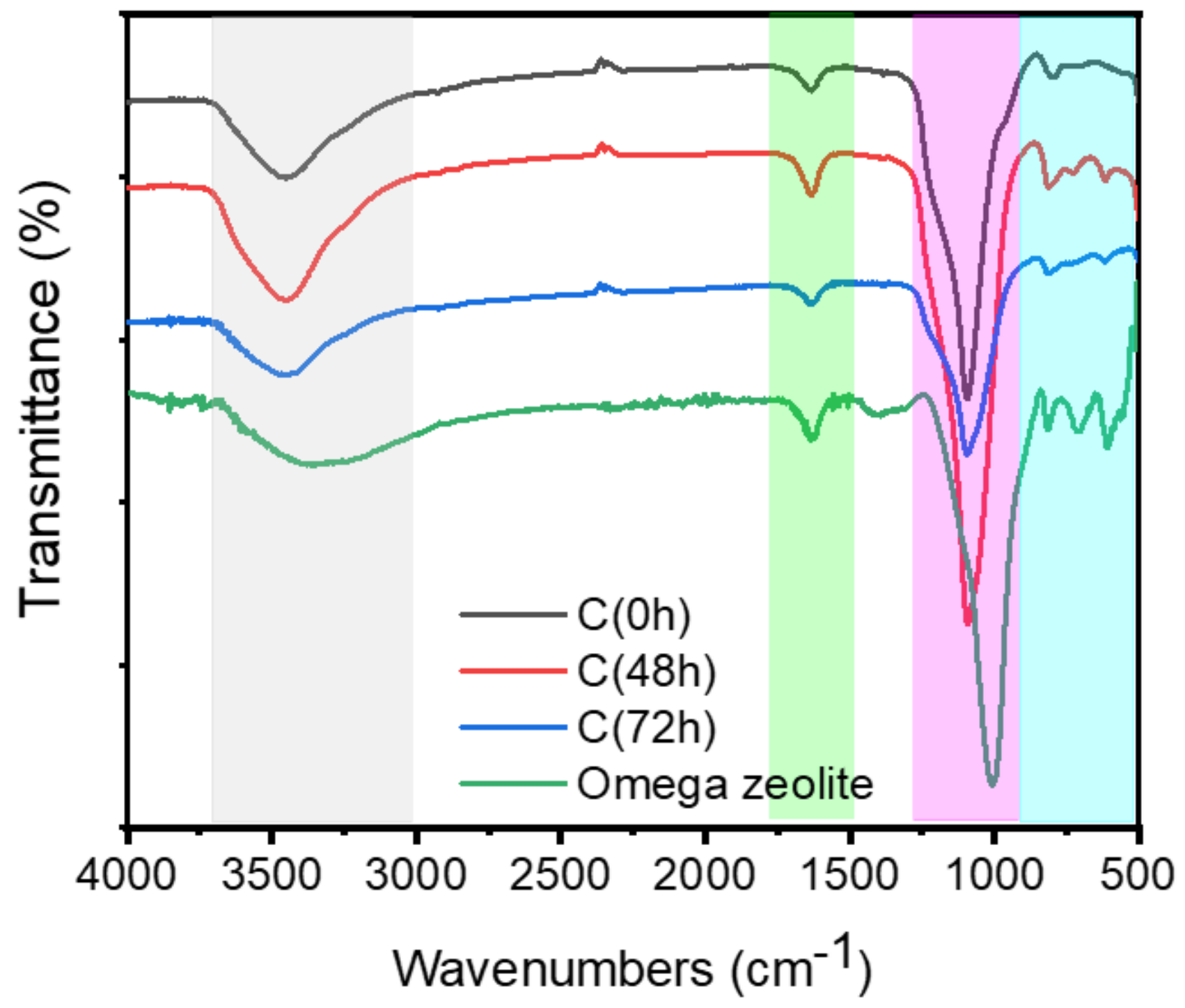

Figure 2

FTIR spectra of the calcined samples 

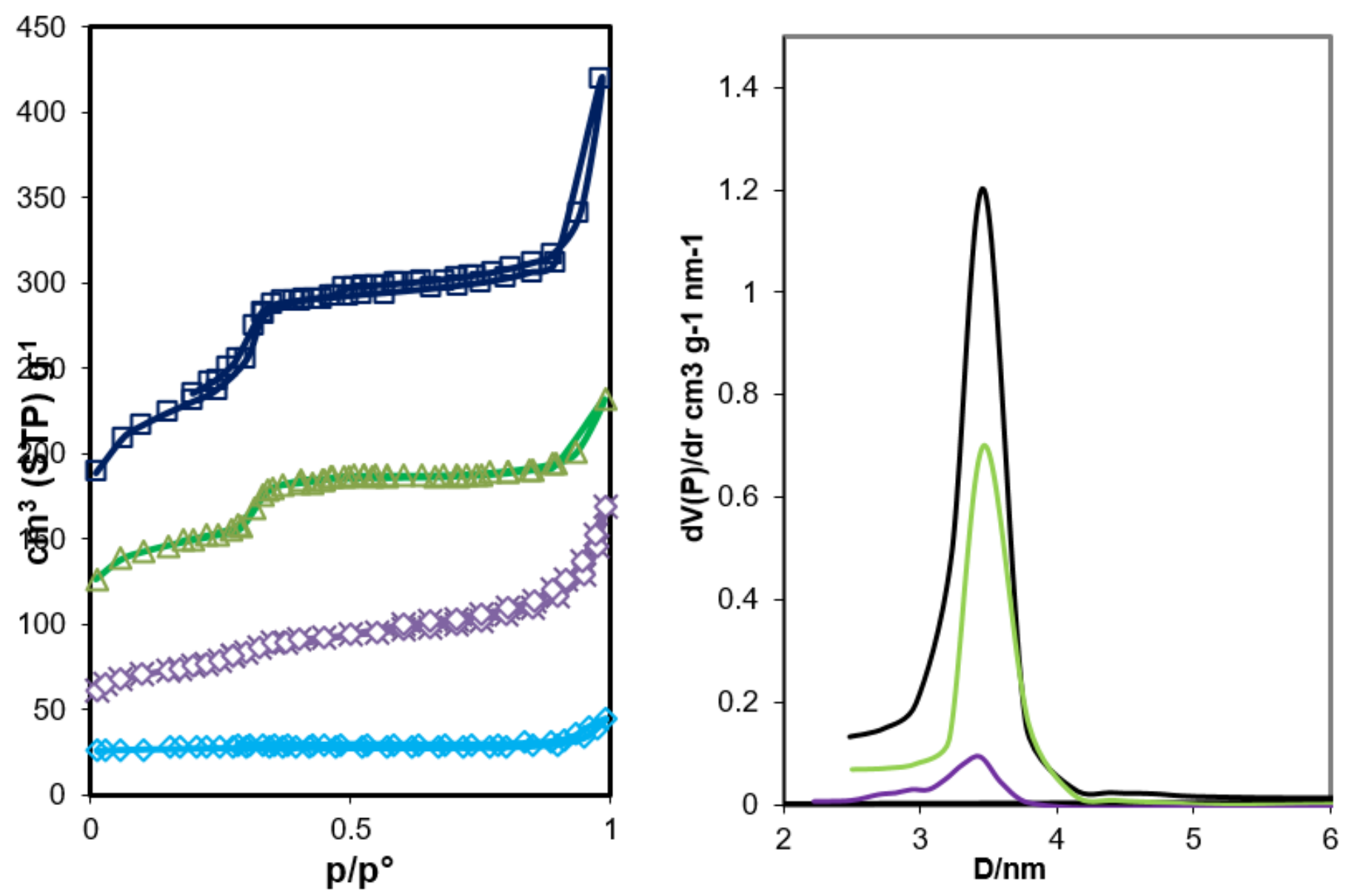

Figure 3

$\mathrm{N} 2$ adsorption-desorption at $77 \mathrm{~K}$ 

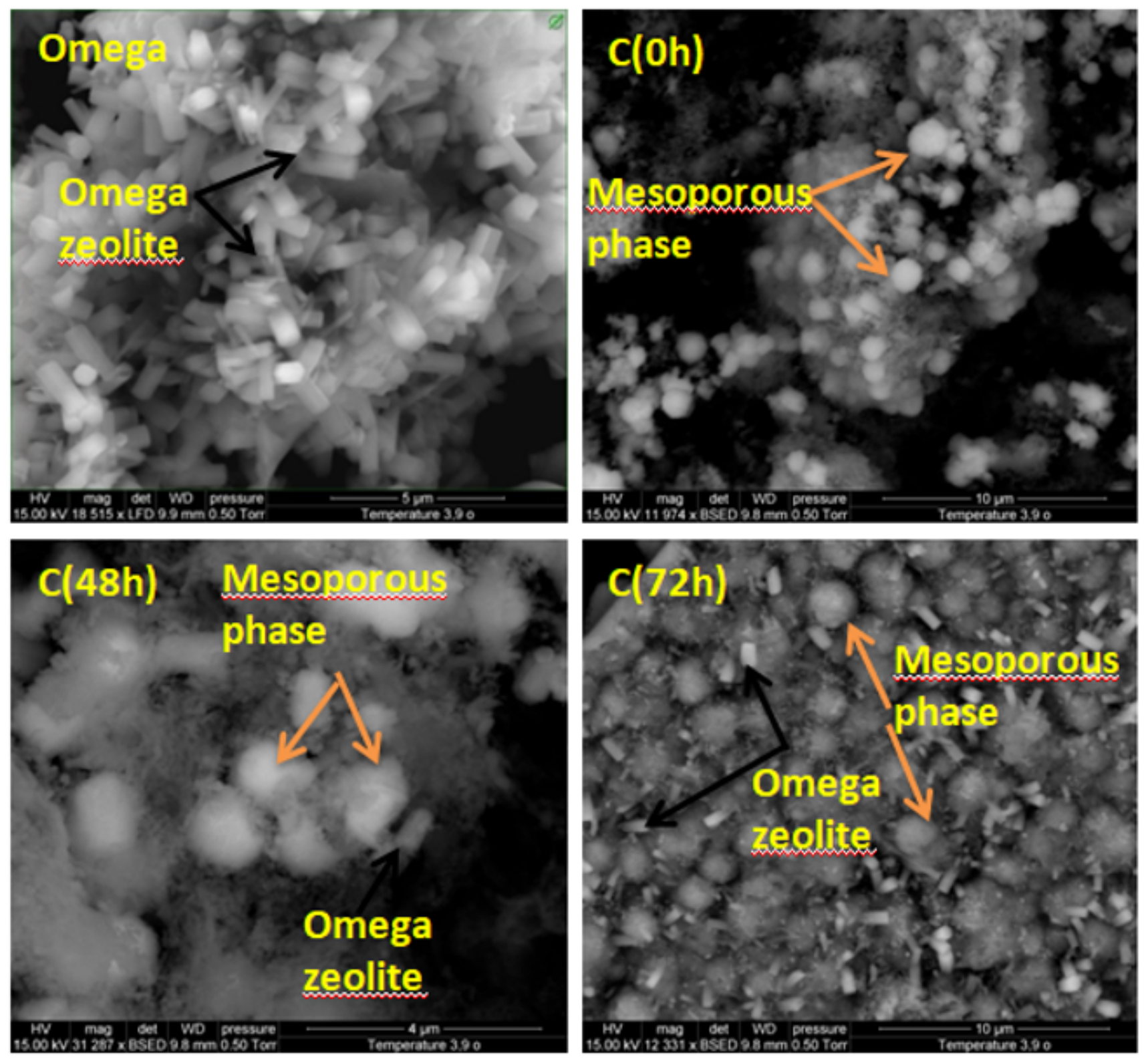

Figure 4

Representative SEM image of omega zeolite and its composite materials 